\title{
The correction of paralytic medial ectropion
}

\author{
G. J. CRAWFORD, J. R. O. COLlin, AND P. A. J. MORIARTY \\ From Moorfields Eye Hospital, City Road, London ECI
}

SUMmary Ten cases of paralytic medial ectropion associated with 7th nerve palsy were treated with a new procedure involving shortening of the medial canthal structures and division of the inferior canaliculus with subsequent marsupialisation. The success of this operation is supported by anatomical and functional studies.

A new approach to the repair of the paralytic medial ectropion associated with 7th cranial nerve palsy is described. The operation involves horizontal lid shortening, tightening of the lax medial canthal tendon, and marsupialisation of the canalicular stump. In patients with long-standing 7th nerve palsy there is gross laxity of the medial canthal tendon (Fig. 1). Previously described procedures have not effectively shortened the medial canthal tendon because of a reluctance to section the inferior canaliculus. In our procedure we deliberately divide the inferior canaliculus medial to the punctum to allow effective lid shortening in the area of maximal lid laxity (Fig. 2).

Resection of the canaliculus is justifiable because the lacrimal drainage system is not functioning normally in these patients anyway. Procedures which attempt to tighten the medial canthal tendon without resection tend only to 'concertina' the long lax

Correspondence to Mr J. R. O. Collin, Moorfields Eye Hospital, City Road, London EC1V 2PD.

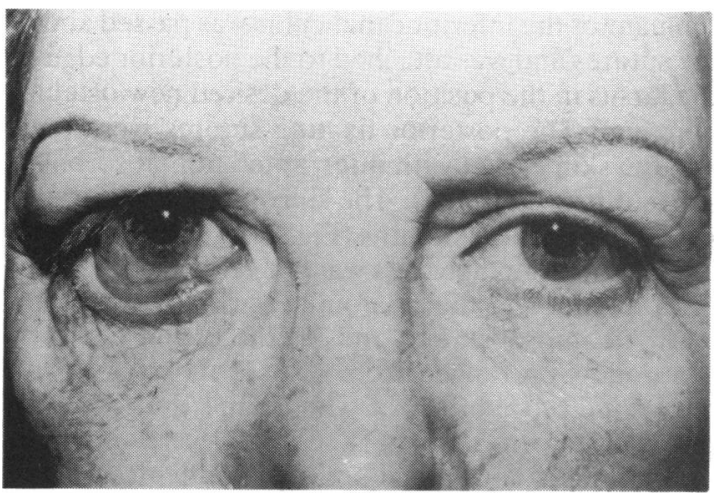

Fig. 1 Patient with long-standing 7th nerve palsy and medial ectropion. functionless canaliculus, with further potential obstruction to flow. Procedures which only attempt to reposition the punctum do not effectively improve physiological drainage.

The lacrimal function studies and results in those patients who underwent our procedure are presented.

\section{Subjects and methods}

Nine patients and 10 lower lids were operated on in the following manner. All had marked paralytic medial ectropion secondary to a 7th nerve palsy, with marked medial canthal tendon laxity. All had presented with annoying epiphora and had a very poor cosmetic appearance (Fig. 1).

The cause of the respective 7 th nerve palsies were congenital (4), postsurgical (e.g., acoustic neuroma) (3), idiopathic (1), bilateral Möbius syndrome (1). Of those involved four were male and five female, with a mean age of 66.7 years at the time of operation.

The procedure was performed under local or

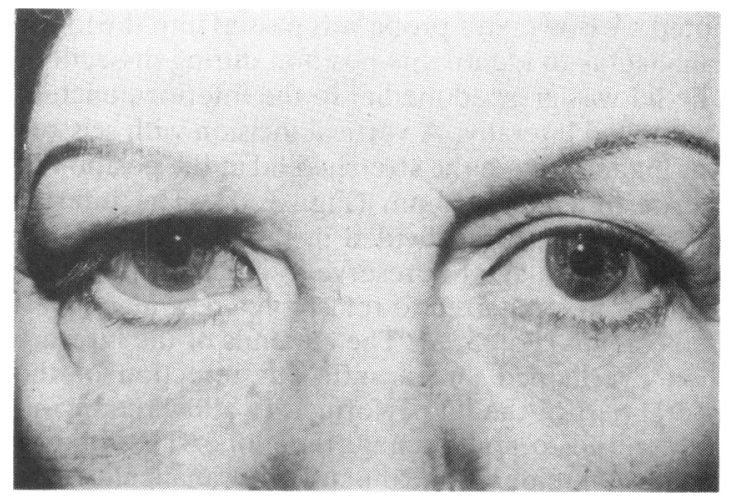

Fig. 2 Same patient postoperatively with silicone tube in situ. 
Fig. 3 Diagrams of operation. (1) Extent and shape of proposed lid resection. (2) Preserved stump of cut inferior canaliculus. (3) Canaliculi intubated and suture placed in posterior limb of medial canthal tendon. (4) Horizontal cross-section showing suture from posterior limb of medial canthal tendon to medial edge of resected tarsal plate. (5) Cut inferior canaliculus above posterior limb of medial canthal tendon with skin closure suture left loose.

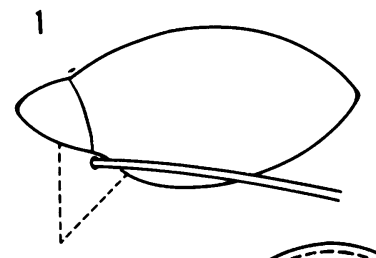

2
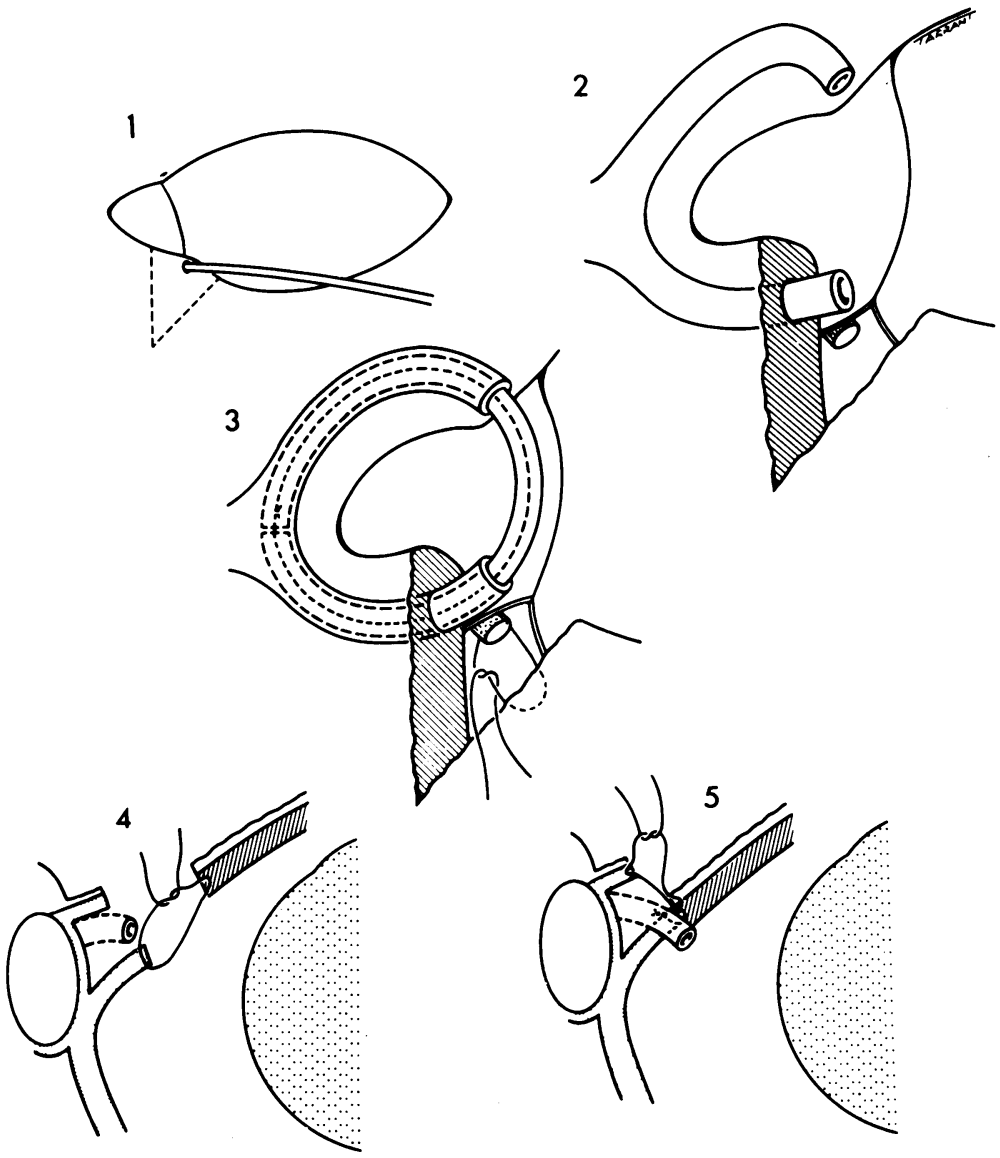

general anaesthesia, but general anaesthesia was preferred because of the degree of manipulation required in the medial canthal region. The lower and upper puncta and canaliculi were cannulated and syringed prior to surgery. In several cases a partial stenosis in the region of the common canaliculus was noted. A Bowman's probe was passed into the lower canaliculus to identify its position during dissection. The lid was grasped medial to the inferior punctum and pulled laterally. A vertical incision with scissors was made through the stretched lid at the position of the desired new osteum (Fig. 3, 1). The inferior canaliculus was not divided in this incision, but an attempt was made to preserve as much of the canaliculus as was required to refashion a new marsupialised osteum (Fig. 3,2). The cut ends of the lid were then overlapped and a sufficient resection of the lateral part of the lid performed to allow the reconstructed lid to approximate the globe. The inferior canalicular remnant and the superior canaliculus were intubated with silicone tubing by means of either a Quickert-Dryden probe $^{1}$ or an eyed pigtail probe in the manner described by Adams $^{2}$ (Fig. 3, 3). The posterior limb of the medial canthal tendon was then identified, and two 6 ' 0 ' long-acting absorbable sutures on a half circle needle were passed through this tendon and through the medial edge of the resected tarsal plate, and left loose (Fig. 3, 4). The remnant of the inferior canaliculus was passed above the sutures and was attached to the posterior edge of the tarsus in the position of the desired new osteum/ punctum. The posterior fixating sutures were tied, and the skin closed with interrupted non-absorbable 6 ' 0 ' sutures (Fig. 3,5). The silicone tube was left in situ for three to six months (Fig. 2).

The operation's success was gauged on (1) its relief of epiphora; (2) the anatomical lid alignment and cosmetic improvement; and (3) the ocular comfort. The follow-up ranged from 3 to 22 months, with a mean of 11.4 months, at which time the following protocol was followed: (1) a subjective assessment of symptomatic and cosmetic improvement; (2) the upper canaliculus was syringed and if patent was temporarily occluded with a gelatin rod; (3) a Jones I 
test was performed in the manner originally outlined by Lester $\mathrm{Jones}^{3}$ to assess lower lacrimal system function and not just patency; (4) if the Jones I test was negative, the lower canaliculus was syringed through to ascertain patency; (5) a dacryocystogram was performed in all cases. There was no difficulty in finding the inferior ostium and cannulation was through this opening.

\section{Results}

Our results are presented in Table 1.

Of the 10 lid procedures only six were examined objectively in the manner outlined above; the remaining four patients replied to a questionnaire. All claimed improvement in the epiphora, and in $90 \%$ there was complete subjective relief of symptoms. All claimed considerable cosmetic improvement.

Of the patients examined five out of six $(83 \%)$ had a positive Jones I test, and in all cases the marsupialised ostium could be cannulated and the inferior lacrimal system was patent to syringing. Furthermore the dacryocystogram gave radiological confirmation of this patency in all cases. In the patient with the negative Jones I test the ostium was positioned too anteriorly. In all cases there was good anatomical approximation of the lower lid to the globe.

\section{Discussion}

The reasons for performing surgery on these patients with paralytic medical ectropion was to reduce the symptoms of epiphora and to improve cosmesis. There are operations that do deal with such problems, all of which are reasonably adequate, but we feel our

Table 1 Results of operation

\begin{tabular}{|c|c|c|c|c|c|}
\hline Case & $\begin{array}{l}\text { Pre-op. } \\
\text { epiphora }\end{array}$ & $\begin{array}{l}\text { Post-op. } \\
\text { epiphora }\end{array}$ & $\begin{array}{l}\text { Jones I } \\
\text { test }\end{array}$ & $\begin{array}{l}\text { Lower } \\
\text { lacrimal } \\
\text { patency }\end{array}$ & $D C G$ \\
\hline $1(R)$ & + & - & + & + & Patent \\
\hline $2(\mathrm{~L})$ & + & - & + & + & Patent \\
\hline 3 & ++ & - & + & + & Patent \\
\hline 4 & ++ & - & $\begin{array}{l}\text { (antero- } \\
\text { placed } \\
\text { osteum) }\end{array}$ & + & Patent \\
\hline 5 & ++ & - & + & + & Patent \\
\hline 6 & ++ & - & + & + & Patent \\
\hline 7 & + & - & & & \\
\hline 8 & ++ & + & & & \\
\hline 9 & ++ & - & & & \\
\hline 10 & + & - & & & \\
\hline
\end{tabular}

DCG=dacryocystogram. alternative gives better results. Such alternative procedures are the Lee medial canthoplasty, ${ }^{4}$ lateral and medial tarsorrhaphies, ${ }^{5}$ and the lateral canthal sling procedure, ${ }^{6}$ but in our experience these procedures are less effective at relieving epiphora. Any form of tarsorrhaphy also has the cosmetic disadvantage of reducing the horizontal palpebral aperture. If there is marked medial canthal tendon laxity, the lateral canthal sling procedure leads to an unacceptable degree of lateral punctal displacement. McCord ${ }^{1}$ described the canaliculostomy part of our procedure in 1980 , when he used it to treat medial lower lid defects associated with neoplastic disease and in the treatment of cicatricial and post-traumatic deformities. He emphasised the need for reattachment of the posterior limb of the medial canthal tendon and not just of the anterior limb. This part of the procedure is technically most challenging and is easier under general anaesthesia. We also agree that it is important for the ostium/punctum to be positioned at the very posterior edge of the wound, and that the ostium should be held open preferably with 8 ' 0 ' long-acting absorbable sutures. We prefer a wedge-shaped horizontal lid resection with the initial cut vertical (Fig. 3,1), because this allows the lateral portion of the lid to be rotated medially, affording lift to the medial lid margin and better skin apposition. This paper has demonstrated, with functional studies, that our technique is safe and very effective.

We have described a procedure of lid shortening with tightening of the medial canthal tendon, in combination with McCord's technique ${ }^{7}$ of marsupialisation of the canalicular stump for the correction of paralytic medial ectropion, associated with 7th nerve palsies. We consider this to be the procedure of choice for these cases.

G. J. Crawford was supported by an F. A. Hadley travelling scholarship from the University of Western Australia.

\section{References}

1 Quickert MH, Dryden RM. Probes for intubation in lacrimal drainage. Trans Am Acad Ophthalmol Otolaryngol 1970; 74: 431-3.

2 Adams AD. Silicone-loop repair of the torn canaliculus. Arch Ophthalmol 1976; 94: 1958-60.

3 Jones LT, Linn ML. The diagnosis of the causes of epiphora. Am J Ophthalmol 1969; 67: 751.

4 Lee OS. Operation for correction of everted lacrimal puncta. Am J Ophthalmol 1951; 34: 575-8.

5 McLaughlin CR. Surgical support in permanent facial paralysis. Plast Reconstr Surg 1947; 2: 25-9.

6 Tenzel RR. Treatment of lagophthalmos of the lower lid. Arch Ophthalmol 1969; 81: 366-8.

7 McCord CD. Canalicular resection and reconstruction by canaliculostomy. Ophthalmic Surg 1980; 11: 440-5. 